\title{
BRIEF COMMUNICATION \\ THE EFFECTS OF REPEATED TEMPERATURE APPLICATIONS TO TESTES ON FERTILITY IN MALE RATS
}

\author{
K. BOWLER \\ Department of Zoology, University of Durham
}

(Received 4th April 1967)

The damaging effect of heat on the germinal epithelium of the testes of a variety of mammals is now well documented and in particular the morphological changes which occur (Chowdhury \& Steinberger, 1964; Steinberger \& Dixon, 1959). This problem, however, has also been studied by following the changes in male fertility after the application of heat to the testes (Young, 1927) and the most comprehensive work to date on rats is that by Elfving (1950). He found that the length of the infertile period depended not only on the temperature but also on the duration of the exposure.

Venkatachalam \& Ramanathan (1962) have studied, in rats, the effects of repeated heat treatments on spermatogenesis in the same individual male. Their results indicated that the germinal epithelium cannot adapt to repeated temperature stresses; however, the significance of their results is difficult to assess because of their experimental procedure, particularly as they did not determine whether the males were temporarily or permanently sterile at the end of the experiments.

The purpose of the present study is to ascertain the effect of repeated heat treatments on fertility in male rats, and so to evaluate the capacity of the testes to adapt to, or recover from, repeated temperature stresses.

Sixty-eight pairs of male and female albino rats were used in this work. The fertility of the pairs was tested at the onset of the experiment and the three males from infertile matings were not used. In subsequent fertility trials each male was placed with its respective female partner for at least 5 days so that the male was present for a complete oestrous cycle.

The males were anaesthetized with an intraperitoneal injection of Nembutal before the application of heat. The testes were heated by immersing the males up to the level of the penis in a water bath, the temperature of which was maintained at $43 \cdot 5 \pm 0 \cdot 1^{\circ} \mathrm{C}$. The duration of heating was $20 \mathrm{~min}$ in all cases.

Eleven males had their testes heated once only and 3 weeks later were placed with their female partner until she became pregnant, Group A males. Group B males had their testes heated at repeated 6-weekly intervals (twice to seven times depending on the individual). The fertility of these males was tested about 5 weeks after each treatment and thus immediately before the 
next heat application. Groups of six males were killed after each of the fertility tests and their testes fixed for a subsequent histological study. The fourteen males remaining alive after the seventh heating were placed with their female partner for 170 days, or until she became pregnant, whichever was the sooner. The day a male recovered fertility is taken as the 22nd day before its female mate delivered her litter.

The mean recovery time of the Group A males which had a single application of heat was $60.0 \pm 1.58$ days, the variation in recovery times between individuals was small, being 52 to 65 days.

The fertility tests made 5 weeks after the second, third, fourth, fifth, sixth and seventh heating were negative at each mating for all animals.

Of the fourteen Group B males remaining after the seventh application of heat only twelve regained fertility within the 170-day recovery period. The mean recovery time of fertility of these twelve males was $108 \cdot 2 \pm 7 \cdot 2$ days, which is statistically different from that of Group A males $(P=0 \cdot 001)$ which received a single heat dose only. The range of recovery dates is also much greater in Group B males, being 67 to 170 days. The female partners of the two males which had failed to regain fertility subsequently became pregnant when placed with normal males.

The results obtained by Venkatachalam \& Ramanathan (1962) are not strictly comparable with those presented above, for they gave their heat doses twice daily over a shorter period. Furthermore, they controlled their experimental temperatures only to within $\pm 1^{\circ} \mathrm{C}$; such a variation, particularly at $44^{\circ} \mathrm{C}$, could have profoundly differing effects on fertility (Elfving, 1960). Consequently it is difficult to assess the significance of the results of their fertility tests. The present work confirms Venkatachalam \& Ramanathan's suggestion that the germinal epithelium cannot adapt to a repeated temperature stress; seven heatings delayed the recovery of fertility by some 48 days as compared to a single exposure. However, it is significant that recovery of fertility occurred in the majority of males even after seven heatings.

The recovery time of 60 days for Group A males corresponds well with the reported 52-day duration of spermatogenesis in rats, Glermont \& Harvey (1965), thus it seems likely that recovery from a single heating takes place from stem cell spermatogonia. The delayed recovery in the seven-times heated males may well reflect an accumulation of severely damaged tubules (where damage may be permanent), as a proportion of tubules will be so damaged at each testes heating (Chowdhury \& Steinberger, 1964).

The significance of these results is that the testes of the rat can withstand repeated heat applications and still recover spermatogenic function, although the repeated treatments do cause a delay in the recovery of fertility. The question, which is raised by these results, is that of the effects on male fertility of repeated treatments at a temperature and time which, as a single treatment, does not cause temporary sterility. This question may be of particular importance in human male fertility.

\section{REFERENCES}

Chowdhury, A. K. \& Steingerger, E. (1964) A quantitative study of the effect of heat on germinal epithelium of rat testes. Am. J. Anat. 115, 509. 
Clermont, Y. \& HArvey, S. C. (1965) Duration of the cycle of the seminiferous epithelium of normal, hypophysectomized and hypophysectomized-hormone treated albino rats. Endocrinology, 76, 80.

Elfvivg, G. (1950) Effects of the local application of heat on the physiology of the testis. Thesis. Helsinki.

Steingerger, E. \& Drxon, W. J. (1959) Some observations on the effect of heat on the testicular germinal epithelium. Fert. Steril. 10, 570.

Venkatachalam, P. S. \& Ramanathan, K. S. (1962) Effect of moderate heat on the testes of rats and monkeys. 7. Reprod. Fert. 4, 51.

Young, W. G. (1927) The influence of high temperature on the guinea pig testis: Histological changes and effects on reproduction. 7. exp. Zool. 49, 459. 